\title{
Why (no) global competition policy is a tough choice
}

\author{
Abigail Tay ${ }^{\mathrm{a}}$, Gerald Willmann ${ }^{\mathrm{b}, *}$ \\ ${ }^{a}$ Department of Economics, Columbia University, New York, NY 10027, USA \\ ${ }^{\mathrm{b}}$ Department of Economics, University of Kiel, 24098 Kiel, Germany
}

Accepted 6 December 2004

Available online 2 March 2005

\begin{abstract}
This paper analyzes the global aspects of competition policy. The effects of a merger in the global marketplace will generally be asymmetric, and consequently lead to a bias in domestic merger decisions. In order to compare different policy regimes, we ascribe general objective functions to the respective authorities and employ a stochastic notion of mergers. We show that under the territoriality principle, the resulting global policy is too lax, whereas when domestic agencies assume extra-territorial powers the resulting policy is inefficiently strict. A global authority would achieve the first best outcome. The gains, however, would be distributed unevenly, which may explain the difficulty of instituting such an authority.
\end{abstract}

(C) 2005 Board of Trustees of the University of Illinois. All rights reserved.

JEL classification: F23; L4

Keywords: Global competition policy; International mergers

\section{Introduction}

The world is rapidly turning into a global market place. Businesses routinely buy from, and sell to, foreign counterparts, companies form alliances and merge across national borders, and the resulting multinationals freely roam the world. Yet, despite the global nature

\footnotetext{
* Corresponding author. Tel.: +1 2128548277.

E-mail addresses: at436@columbia.edu (A. Tay), gerald@email.uni-kiel.de (G. Willmann).
} 
of the game, there is no global competition authority to safeguard competition in this global market. All we see are modest attempts at cooperation between national authorities. And as recent disputes - for example, over the G.E. \& Honeywell merger proposal - demonstrate, these attempts are modest indeed. At the same time, the EU and US authorities have begun to exercise extra-territorial powers, with the European Directorate General Competition willing to take on all-American mergers.

In this paper we investigate the decisions of national competition authorities, the resulting policy at the global stage, and the decisions that a hypothetical global authority would take. At a theoretical level, we allow the competition authorities to maximize general objective functions. Without assuming a particular market structure, these depend on the merging companies' profits, the profits of the other suppliers, the surplus of the buyers, and on the geographical distribution of each group's surplus. In a two-country setting, we analyze the global policy outcomes under different policy regimes. Under a symmetric, non-cooperative territoriality regime, the resulting global policy is inefficiently lax. By contrast, the noncooperative exercise of extra-territorial powers leads to an inefficiently strict policy outcome. This result is important because it refutes the common perception that the lack of a global authority implies too lax a policy. A would-be global authority achieves the first-best because it internalizes the effects on all the parties involved. Finally, an asymmetric, non-cooperative regime of territoriality versus extra-territorial power reveals that the powerful country stands to lose from the institution of a global authority, unless unrealistic side-payments are made.

We are not the first to analyze international competition policy. There is a considerable body of literature that offers verbal discussions of the subject. Good overviews are provided in Evenett, Lehmann, and Steil (2000) and Kleinert and Klodt (2000). Guzman (1998) shows by example many of the predictions that we derive rigorously in this paper. There are also previous theoretical studies. Examples include Barros and Cabral (1994), Head and Ries (1997), Bond (1997), Richardson (1999), and Horn and Levinsohn (2001). These studies assume more or less specific models of oligopolistic competition and apply these in an international context. The two contributions that are most closely related to our work are Cabral (2002) and Beelders and Özden (2001). Cabral (2002) interprets international competition policy cooperation as a repeated game. His theoretical approach is similar to ours even though he considers neither territoriality nor asymmetric regimes. Beelders and Özden (2001) offer an empirical investigation of European competition policy towards international mergers that is based on the theory of Barros and Cabral (1994) and ultimately on Farrell and Shapiro (1990).

The remainder of the paper is organized as follows. In Section 2, we describe the institutional set-up of competition policy, focusing on Europe and the US. Section 3 presents our theoretical framework. Section 4 emphasizes the scope for conflict between national authorities. In Section 5, we compare different policy regimes. Section 6 offers concluding remarks.

\section{Institutional setting}

Before we formally analyze global competition policy, it is useful to take a closer look at the institutional set-up. That is, the agencies that are in charge of competition policy, 
the guidelines that they (supposedly) follow, and the changes - if any - that have been proposed with regards to these procedures. We will concentrate on the Brussels-based Directorate General IV (Competition) of the European Union (DG4 from now on) and the Department of Justice (DoJ) as well as the Federal Trade Commission (FTC) on the US side. We first consider the American side, because in Europe there is the additional complication of whether the European or a national authority takes on a specific case.

The legal basis for competition policy in the United States is the Clayton Act and the Hart-Scott-Rodino Antitrust Improvements Act of 1976. The latter requires parties contemplating a merger of a certain size ${ }^{1}$ to notify the authorities by filing the relevant forms and pay a filing fee. Once the forms are filed there is a 30-day waiting period during which the DoJ or FTC review the filings. Cases are allocated to either agency according the agency's expertise and past experience with given industries. If the transaction appears to pose a threat to competition the agency involved will issue a so-called "second request" for additional information.

After the information requested has been received, there is a new 20-day waiting period during which the merger proposal is analyzed according to the Horizontal Merger Guidelines that were jointly issued by the DoJ and FTC in 1992. Under these guidelines, the agency in charge will first determine the relevant product and geographical market. It will then measure concentration in the defined market using the Herfindahl-Hirschmann index and will assess the possibility of market entry. Finally, it will analyze the competitive effects of the merger and contrast them with possible efficiency gains. If the agency concludes that the merger would be harmful, it will challenge the merger. It can either seek an injunction in federal court, typically asking for a divestiture, or, in the case of the FTC, issue a "cease and desist" order.

On the European side, we focus on the DG4 and leave aside the national authorities that usually do not handle cases of international reach. The legal basis for competition policy at the European level are articles 85, 86, 89, and 90 of the Treaty of Rome and European Council regulation 4064/89. The latter stipulates that the following criteria have to be met for a merger to be considered by DG4: the combined worldwide turnover exceeds 5 billion euros and the Community-wide turnover of each is more than 250 million euros. In addition, it exempts those mergers where each party achieves more than two thirds of its Community-wide turnover in the same member country, as such cases would be referred to the corresponding national authority.

As in the US, the European Commission requires notification of mergers. If the case meets the above criteria and raises serious doubts, DG4 will initiate proceedings. It can issue a request for further information, just as its US counterpart. DG4 will then appraise the potential concentration by taking into account the need to maintain and develop effective competition and the market position of the merging companies. This emphasis on dominance (the "substantive test") contrasts to some extent the substantial lessening of competition

\footnotetext{
1 Premerger notification is required if either party has net assets or total annual sales in excess of 100 million USD and the other party has sales or assets of more than 10 million USD and if, as a result of the merger, the acquiring party will hold more than 15 million USD of the acquired party's stock/assets or at least $50 \%$ of an issuer that has at least 25 million USD in net sales or assets.
} 
(SLC) approach of other countries, including the US. If DG4 determines, after investigating the case, that the merging entity would acquire a dominant position it will declare the merger incompatible with the Common Market and can impose fines of up to $10 \%$ of combined worldwide turnover. DG4 thus has considerable leverage in its decisions. In contrast to the US, the onus is on the merging parties to appeal against its decisions to the European Court of Justice.

Recently, reforms have been proposed by DG4 to improve its procedures. Although it does not intend to abandon the dominance approach, it wants to give greater consideration to efficiency gains and consumer surplus. It also plans to expand its economic expertise ${ }^{2}$ and set clear best practice rules. Furthermore, it promises greater flexibility in timing decisions, a move aimed mainly at facilitating synchronized, joint investigations with its US counterparts. Finally, there is to be more scope for referral between DG4 and the respective national competition authorities.

On the international scene, the emphasis has so far been mainly on providing technical assistance to less developed countries and sharing information on specific cases among developed countries. The US has been promoting the Global Competition Network that organizes technical assistance for less developed countries and has helped many of them set up competition authorities. The US also has various bilateral agreements with other developed countries, the most important being the treaty with the EU. The aim of this limited cooperation is to share information on particular cases, to coordinate the timing of investigations, and ultimately to achieve a convergence of objectives. The limited nature of this cooperation is best illustrated by a caveat limiting the exchange of information. The exchange of information is only to take place as long as the private parties involved do not object.

\section{Analytical framework}

In this section, we lay out the analytical framework that we will use to investigate international mergers and global competition policy. Our aim is to provide a general framework that can accommodate different political objectives and possible market structures. Without relying on specific assumptions, the approach presented here can nest many of the specific models that have been proposed in the literature. It is thus similar in spirit to the modelling approach of Bagwell and Staiger (2002) in the GATT/WTO context. ${ }^{3}$ Our set-up is meant merely to guide us in identifying the different effects that could potentially determine the competition authorities' considerations. Ultimately, we count on the data to inform our views on these issues.

Consider a horizontal merger in a particular market. We can distinguish three groups of market participants: on the supply side, there are the companies (two in most cases) that intend to merge and the other suppliers that are not involved in the merger. On the demand side, we have the buyers of the product. We can thus decompose the effect of the merger according to which of these three groups is affected.

\footnotetext{
${ }^{2}$ For example, it has recently hired a chief economist.

${ }^{3}$ We are grateful to Rob Feenstra for pointing out this analogy.
} 
Let $\prod_{\text {in }}$ denote the profits of the merging companies, insiders for short. The merger will most likely have a positive effect on these profits, because the insiders will only propose the merger if it is profitable. The profits of the other suppliers, outsiders for short, we denote by $\prod_{\text {out }}$, and the surplus of the buyers by CS. ${ }^{4}$ How these two groups are affected by the merger depends on two opposing effects: the change in the intensity of competition and the potential synergies between the merging companies. If the former effect dominates then the outsiders benefit from the reduced degree of competition and the buyers are worse off. If, on the other hand, the efficiency gains created by the merger are dominant then the buyers benefit whereas the competitors are worse off.

Given our interest in international competition policy, we have to take into account the international dimension of a merger. To this end, we need to consider at least two countries. For the most part, we will indeed limit our analysis to two, not only for simplicity, but because there are in fact two heavy-weight players on the international stage: the EU and the US. ${ }^{5}$ The international aspect implies two additional, geographical dimensions: where a particular surplus arises, and where its beneficiary is located. Take outsiders' profits, for example. Along the first dimension, we distinguish the companies' profits earned in the US from the profits they earn in the EU market. This distinction only matters if markets are segmented, of course, but in line with our emphasis on generality we allow for this possibility. Furthermore, with regards to the second dimension, it matters which share of the companies is located in the EU and in the US, respectively. ${ }^{6}$

We now formulate general objective functions that the respective national competition authorities seek to maximize when handing down a decision on a particular merger case:

$$
F^{j}\left(\Pi_{\text {in }}, \Pi_{\text {out }}, \mathrm{CS} ; S^{j}\right), \quad j=\mathrm{EU}, \mathrm{US}
$$

where $S^{j}$ denotes a vector of shares $\left(\mathrm{s}_{\text {in }}^{j}, \mathrm{~s}_{\text {out }}^{j}, \mathrm{~s}_{\mathrm{CS}}^{j}, \mathrm{~d}_{\mathrm{in}}^{j}, \mathrm{~d}_{\mathrm{out}}^{j}, \mathrm{~d}_{\mathrm{CS}}^{j}\right)$ that indicate what percentage of each surplus stems from transactions in the domestic market (s for source) and what percentage of each surplus accrues to domestic residents (d for destination). Obviously, these shares are symmetric in the sense that $S^{\mathrm{EU}}=(1, \ldots, 1)-S^{\mathrm{US}}$. In other words, we assume that the respective objectives depend on the surpluses of the three groups, how much of them originates from each country's market, and how much ends up in the pocket of domestic residents. When the competition authority has to decide on a particular merger case, it will attempt to quantify how the merger affects the different components of $Z$ while also taking into account their geographical distribution. It then chooses the course of action - blocking the merger, waving it through, or requiring divestitures - that maximizes its objective function.

To better understand these general objective functions, let us consider one concrete example: national welfare maximization. If the competition authority seeks to maximize

\footnotetext{
${ }^{4}$ Note that despite our implicative notation these buyers could very well be companies.

${ }^{5}$ Later on, we will extend our analysis to consider a fringe of smaller countries.

${ }^{6}$ Ideally, we would like to allocate the profits of a company to each country according to the company's ownership structure. That is, the company's profits should accrue partly to the EU and partly to the US depending on what percentage of its shares is held by Americans and Europeans, respectively.
} 
national welfare, then its objective function takes the form:

$$
F^{j}\left(\Pi_{\text {in }}, \Pi_{\text {out }}, \mathrm{CS} ; S^{j}\right)=\mathrm{d}_{\text {in }}^{j} \Pi_{\text {in }}+\mathrm{d}_{\text {out }}^{j}+\mathrm{d}_{\mathrm{CS}}^{j}
$$

In this case, the domestic competition authority maximizes the sum of the respective shares of each surplus which accrue to domestic residents. The absence of any $S^{j}$ indicates that the authority only considers what accrues to domestic residents, not where it came from. This would change as soon as we introduced taxes, spillovers, unemployment, etc. In any case, the s's and the d's will tend to correlate due to home bias. For segmented markets, $\mathrm{d}_{\mathrm{CS}}^{j}$ exactly equals $\mathrm{s}_{\mathrm{CS}}^{j}$.

\section{Potential conflict}

After having formalized the competition authorities' objectives, let us focus on how conflicts can arise over particular merger cases. From the objective function (1) we see that the most straight-forward explanation of such conflicts would be that the two authorities have different objectives-that is, their respective objective functions take on different functional forms. Statements by members of the EU and US competition authorities suggest that this is perceived to be the main reason behind the disputes that have arisen. It is argued that the US authorities give greater consideration to insider profits and consumer surplus than their EU counterparts who place relatively more weight on the interests of the competitors. To overcome these differences, it is thought, one only needs to hold talks for long enough, in order to eventually agree on a common objective function.

However, it seems unlikely that a common objective function would align national interests. On the contrary, even a common objective function leaves ample room for disagreement because the geographical distribution of surpluses will most likely be asymmetric and enters each country's objective function under opposite signs. Take a merger proposal that involves two US companies. The merging companies profits accrue mainly in the US. Even if the US competition authority had the same objective function as its EU counterpart, it would be more likely to approve the merger, because a considerable part of the gain goes to the US. Or suppose the competitors were mostly located in Europe, then the EU competition authority might be more likely to oppose the proposal because the potential harm would mostly be inflicted on European companies.

Clearly, in both cases it would appear as if the European DG4 cared more for competitors whereas the FTC or DoJ give greater consideration to the companies that contemplate a merger. Ultimately, the question whether objective functions differ is an empirical one. ${ }^{7}$ It is clear from our discussion, though, that identical objectives are not sufficient to ensure identical decisions and therefore do not necessarily prevent conflict between national authorities.

\footnotetext{
${ }^{7}$ We plan to answer this question in future work by estimating policy reaction functions for each competition authority and statistically testing whether they are equal.
} 


\section{Comparison of policy regimes}

Knowing the scope for conflict, we now analyze the outcome under different policy regimes. The four regimes we consider are (1) a non-cooperative regime where neither country assumes extra-territorial powers but instead limits its decisions to purely national mergers. This is the so-called territoriality principle, that is practiced - for lack of power perhaps - by many smaller countries. We contrast this with (2) a non-cooperative regime where both authorities assume extra-territorial powers. This is the status-quo between the EU and the US. We then analyze (3) the cooperative solution of a global competition authority. Finally, as a way of explaining why such an authority has not yet been established, we compare it to (4) an asymmetric, non-cooperative policy regime where one country exercises extra-territorial powers whereas the other country is limited (or limits itself) to territoriality.

Before we embark on this analysis, however, let us formalize the concept of a merger by making use of the concepts introduced earlier. Any merger will cause a change in the functional value of both countries' objectives. We therefore model mergers as the realizations of a bivariate stochastic process $\left(\Delta F^{j}, \Delta F^{-j}\right)$ that is assumed to follow an identically and independently distributed bivariate uniform distribution over $[-1,1]^{2}$. The choice of distribution is admittedly arbitrary. Yet, for lack of a better prior it serves as a useful starting point. Furthermore, we assume that half of the cases happen inside the borders of either country and therefore fall under its jurisdiction in a narrow, geographical sense. This assumption could easily be relaxed to allow for asymmetric distributions. ${ }^{8}$ We can then derive expected pay-offs under each policy-regime and compare the different outcomes. In doing so, we will not emphasize the absolute value of the pay-offs, which depends crucially on the particular distribution chosen, but rather the relative ordering.

\subsection{Territoriality principle}

When both countries abide by the territoriality principle, each competition authority can only block merger cases that fall under its jurisdiction, i.e. exactly half the cases. And it approves mergers only if they do not reduce the value of its objective function. The outcome is depicted in Fig. 1. In the northeastern quadrant all cases are approved because they are beneficial for both countries. In contrast, none of the cases in the southwestern quadrant are approved because these cases make both countries worse off and are therefore blocked irrespective of whose jurisdiction they fall under. More interesting are the cases in the northwestern and southeastern quadrants. All these cases are beneficial for one and negative for the other country. Therefore half of these cases are blocked and the other half approved because each country has jurisdiction over, and can block, only half of these cases.

Let us now calculate the pay-offs resulting from this regime. The outcome is clearly symmetric so the expected pay-offs will be identical for both countries. They amount to:

$$
E(\Delta F)=E\left(\Delta F^{*}\right)=\frac{1}{8}+\frac{1}{16}-\frac{1}{16}=\frac{1}{8}
$$

\footnotetext{
${ }^{8}$ Note that we do not allow the locational choice to become endogenous. Abstracting from this possibility seems justified given the size and long histories of most companies that contemplate international mergers.
} 


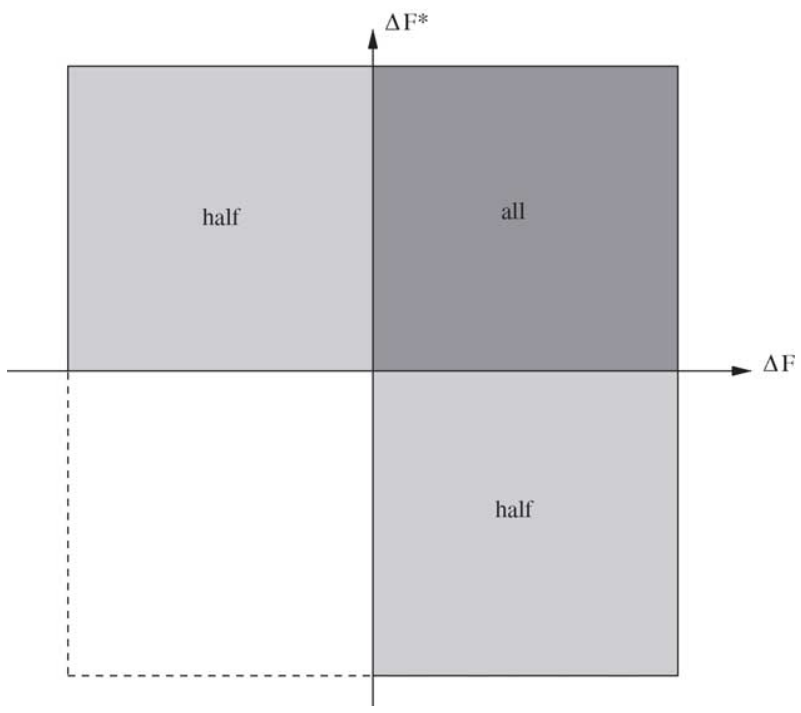

Fig. 1. Territoriality principle.

The first term corresponds to the northeastern quadrant - a probability mass of $1 / 4$ times an average pay-off of $1 / 2$ - while the second and third term represent the northwestern and southeastern quadrants (the mapping from terms to quadrants depends on the country) and off-set each other. For future reference, note that the total expected pay-off under this regime is $E\left(\Delta F+\Delta F^{*}\right)=1 / 4$.

\subsection{Extraterritoriality}

Let us turn to the second regime. Both countries exercise extra-territorial powers in a non-cooperative way. This is the status-quo between the EU and the US. Both unions block every merger that would be harmful to their respective objective. Fig. 2 depicts the outcome of this regime. The southwestern and northeastern quadrants are unchanged. What has changed are the northwestern and the southeastern quadrants. Since both countries now assume the power to block every merger that harms their interests, none of these merger proposals go through. The calculation of the expected pay-off is straight-forward:

$$
E(\Delta F)=E\left(\Delta F^{*}\right)=\frac{1}{8}
$$

We only have the term corresponding to the northeastern quadrant. However, the expected pay-off is exactly the same as under the previous policy regime because previously the other terms offset each other whereas here they simply do not appear at all. The total expected pay-off is also the same as before, namely $E\left(\Delta F+\Delta F^{*}\right)=1 / 4$.

Although they both give rise to exactly the same expected pay-offs, there exists a substantial difference between these two non-cooperative, symmetric policy regimes. The territoriality principle implies a rather lax competition policy on the global stage, in the sense 


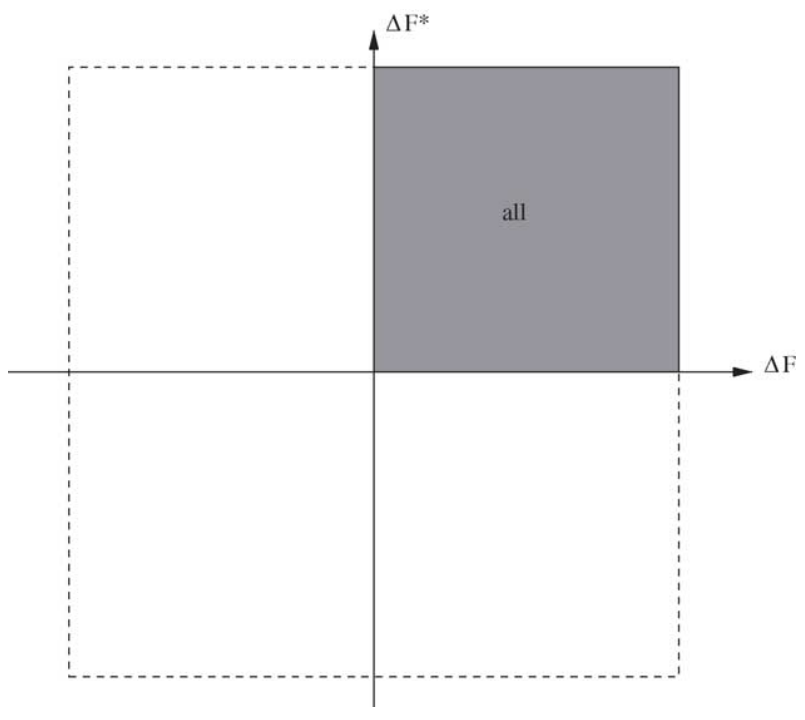

Fig. 2. Extra-territorial powers.

that very few mergers are blocked. The regime with extra-territorial powers, on the other hand, leads to a rather restrictive competition policy. Many mergers are blocked because both authorities have the opportunity to do so.

\subsection{Global authority}

Let us now turn our attention to a (hypothetical) global authority. Under global cooperation, both countries have to agree on an objective function for the global authority. We assume - for simplicity and because the countries we have in mind are of equal size - that the agreed upon objective function is the sum of the respective national objectives. ${ }^{9}$ The global competition authority will then block those mergers whose total expected pay-off is negative and approve all other cases. This outcome is depicted in Fig. 3. The shaded area represents the mergers that produce a positive total pay-off and that are therefore approved by the global authority. All other cases southwest of the negatively sloped diagonal are blocked because they would lead to a negative total pay-off.

Let us calculate the individual expected pay-offs under this regime. Again the situation is symmetric so that the expected pay-offs are identical for both countries. They amount to:

$$
E(\Delta F)=E\left(\Delta F^{*}\right)=\frac{1}{8}+\frac{1}{12}-\frac{1}{24}=\frac{1}{6}
$$

The first term is familiar by now and corresponds to the northeastern quadrant. The second and third term represent the integrals for the northwestern and the southeastern

\footnotetext{
${ }^{9}$ Note that Nash bargaining, for example, does not seem appropriate here as we view the global authority as the decision maker.
} 


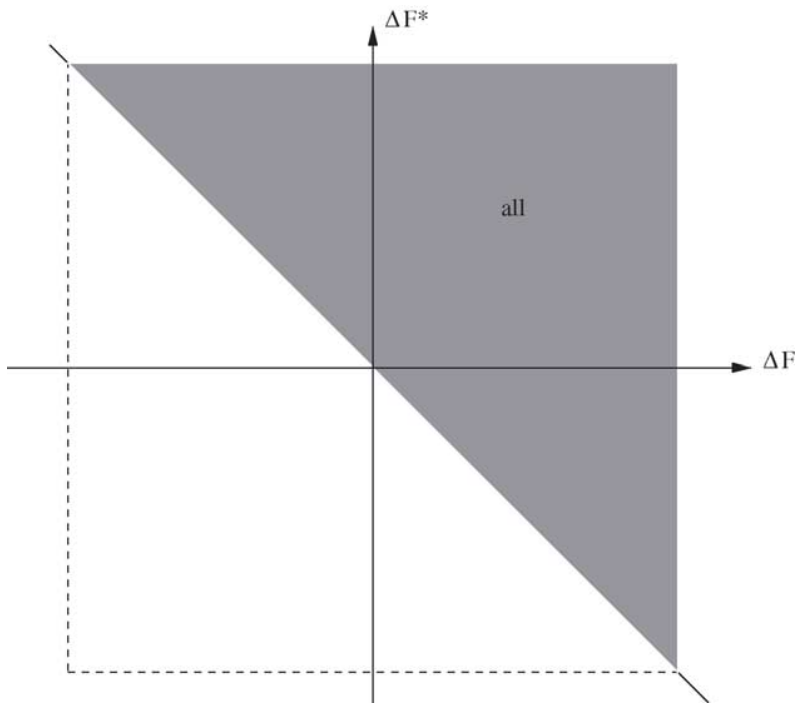

Fig. 3. Global authority.

quadrants (the mapping depends on the country). The total expected pay-off amounts to $E\left(\Delta F+\Delta F^{*}\right)=1 / 3$.

Comparing pay-offs, we clearly see that the cooperative regime dominates the two noncooperative policy regimes. This is not surprising, given that only the cooperative regime takes into account cross border effects or, put differently, internalizes transborder externalities. In fact, the global authority achieves the first best outcome. Both non-cooperative regimes are suboptimal. The territoriality principle errs on the side of too lax a global competition policy, whereas with extra-territorial powers we see too strict a policy. Note especially this last comparison. It implies that the common perception that the lack of a global competition authority necessarily implies too lax a policy in the global market place is misleading. On the contrary, the current policy regime without a global authority can lead to too strict a policy because both authorities can block mergers and the ultimate outcome resembles an order statistic.

\subsection{Asymmetric regime}

The above comparison of pay-offs obviously begs the question, why no global authority has been established yet, even though it would improve pay-offs all around. A possible explanation could be that the situation is not necessarily symmetric. A fringe of smaller countries is currently unable to exercise extra-territorial powers of their own, but would certainly demand a say in deciding the objectives of a global authority.

To analyze such an asymmetric setting, consider the (simplified) situation where one country exercises extra-territorial powers while the other side does not. Fig. 4 depicts this situation. The expected pay-offs are no longer identical. The expected pay-off for the country 


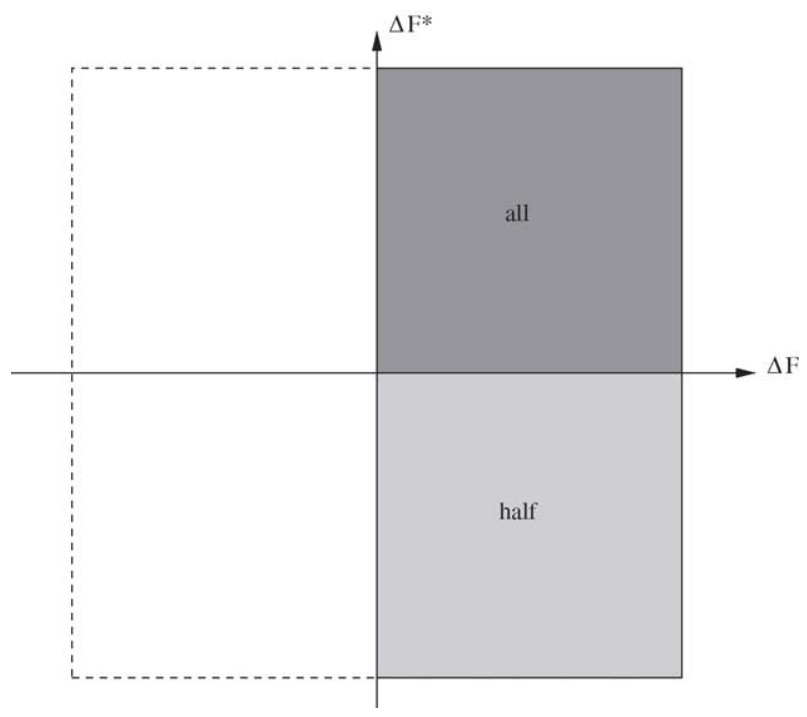

Fig. 4. Territoriality vs. extra-territorial power.

with extra-territorial powers (depicted along the horizontal axis) amounts to:

$$
E(\Delta F)=\frac{1}{8}+\frac{1}{16}=\frac{3}{16}>\frac{1}{6}>\frac{1}{8}
$$

whereas the country without such power (on the vertical axis) can only expect a pay-off of:

$$
E\left(\Delta F^{*}\right)=\frac{1}{8}-\frac{1}{16}=\frac{1}{16}<\frac{1}{8}<\frac{1}{6}
$$

The first term is again the same. The northwestern and southeastern quadrants are decisive. Whereas the country with extra-territorial power succeeds in blocking every merger that harms its interests, the country that is limited to territoriality can only block half of the merger cases in the southeastern quadrant, namely those that fall within its jurisdiction. This explains the different pay-offs. Clearly the outcome for the powerful country dominates the result for the powerless country. And the total expected pay-off of $E\left(\Delta F+\Delta F^{*}\right)=1 / 4$ shows that this regime is inefficient.

More importantly, the outcome for the powerful country under this regime (3/16) dominates its expected pay-off from a global authority (1/6), leave alone the expected pay-offs from the non-cooperative symmetric regimes (1/8). The powerful country would therefore object to the institution of a global authority. Note two interesting implications of these results. First, either heavy-weight would be better off if the other did not exercise its extraterritorial power. This explains the heated exchange of arguments, when a disputed merger case arises. Second, the EU and the US prefer bilateral cooperation in competition matters over a truly global arrangement. This conclusion seems to be borne out by the current situation.

Given that the institution of a global authority leads to the first-best policy, the cooperative regime would potentially be beneficial for all parties involved if we allowed for transfer 
payments among countries. However, the sequential and uncertain nature of the policy decisions cast doubt on the viability of such side-payments. In line with our doubts, such payments have so far played no role in the public debate on global competition policy.

\section{Conclusion}

In this paper, we have analyzed international competition policy under different policy regimes. The driving force behind our work is the crucial insight that domestic competition policy has international repercussions when companies operate in global markets. Consider Microsoft as a case in point. Most of Microsoft's profits accrue in the US. On the other hand, its customers and potential competitors are located around the globe. This geographical mismatch of Microsoft's profits on the one hand and the potential surplus of other market participants on the other will most likely bias the decisions of domestic competition authorities.

The theoretical framework we use ascribes general objective functions to these competition authorities, be they domestic or global. In our view, this general approach is appropriate because market conditions vary especially in an international context. More importantly, it is sufficient to obtain interesting results. As for the objective of competition policy, we model mergers as random occurrences which in line with reality have asymmetric effects on the two countries under consideration.

We use this framework to compare four different policy regimes. Under the territoriality principle, domestic authorities can block only mergers that fall under their jurisdiction. Consequently, they non-cooperatively block too few mergers and the resulting competition policy in the global marketplace is too lax. When domestic authorities assume extra-territorial powers, on the other hand, they between them block too many mergers and the resulting policy is too strict. This result contrasts starkly with the common perception that the lack of a global competition authority implies too lax a policy.

Whether policy is too lax or too strict, both non-cooperative, symmetric regimes give rise to suboptimal outcomes. Only a global authority can internalize the transborder externalities and thus achieve a first best global competition policy. In addition, it would to some extent free developing countries of the need to invest precious resources into setting up their own national agencies. This raises the question why such an authority does not yet exist, and is not even in the planning stages. The international talks that have taken place are clearly not sufficient as we have hopefully convinced the reader. The answer to this question can be seen by considering an asymmetric non-cooperative regime where one side wields extraterritorial powers whereas the other side is limited to territoriality. This represents the current situation between the EU and US on the one hand and a fringe of less powerful players on the other. We show that moving to a global authority starting from such a situation implies gains that are distributed unevenly, inhibiting the creation of a global authority — unless side-payments were possible which seems unlikely given the stochastic nature of this policy area.

In terms of future work, much remains to be done. In a sense, this paper constitutes a research proposal. The general objective functions we ascribe to the competition authorities need to be estimated. Once we have the estimates we can test whether the US and EU objectives with regards to competition policy really differ. If they do not, it will be clear that 
the conflicts that have arisen and are likely to arise in the future are caused not by different objectives but by the asymmetry of effects. Taking this one step further, if the objectives are indeed similar, one will conclude that the objective function of any future global authority must also be the same. We could then simulate the decisions that such an authority would have taken in specific cases.

\section{Acknowledgements}

We are grateful to Daniel Acre, Tim Bresnahan, Theo Eicher, Simon Evenett, Rob Feenstra, Keith Maskus, and to seminar participants at the University of Washington, the Midwest meeting in Pittsburgh, the Conference on Competition, Contracts, and International Trade in Kiel, the CEPR Workshop on Competition Policy in International Markets in Toulouse, as well as the Conference on The Regulation of Development and The Development of Regulation at the University of Illinois for helpful comments and discussions. The usual caveat applies: all errors are ours.

\section{References}

Bagwell, K., \& Staiger, R. (2002). The economics of the world trading system. MIT Press.

Barros, P. P., \& Cabral, L. (1994). Merger policy in open economies. European Economic Review, 38, $1041-1055$.

Beelders, O., \& Özden, C. (2001). Coordination of competition policies: Empirical evidence from the European Union and the United States (mimeo). Emory University.

Bond, E. (1997). Competition policy in customs unions: Theory and an example from U.S. history. Penn State.

Cabral, L. M. B. (2002). International merger policy coordination (mimeo). New York University.

Evenett, S., Lehmann, A., \& Steil, B. (Eds.). (2000). Antitrust goes global: What future for transatlantic cooperation. London: Royal Institute of International Affairs.

Farrell, J., \& Shapiro, C. (1990). Horizontal mergers: An equilibrium analysis. American Economic Review, 80(1), $107-126$.

Guzman, A. T. (1998). Is international antitrust possible? New York University Law Review, 73, 1501-1548.

Head, K., \& Ries, J. (1997). International mergers and welfare under decentralized competition policy. Canadian Journal of Economics, 30(4b), 1104-1123.

Horn, H., \& Levinsohn, J. (2001). Merger policy and trade liberalization. Economic Journal, 777(470), $244-276$.

Kleinert, J., \& Klodt, H. (2000). Megafusionen: Trends Ursachen und Imp-likationen. Kieler Studien 302, Institute for World Economics.

Richardson, M. (1999). Trade and competition policy: Concordia discors. Oxford Economic Papers, 51, 649-664. 